\title{
Factors affecting the HIV/AIDS epidemic: an ecological analysis of global data
}

\author{
*Mondal $\mathrm{MNI}^{1,3}$, Shitan $\mathrm{M}^{1,2}$
}

1. Laboratory of Computational Statistics and Operations Research, Institute for Mathematical Research University Putra Malaysia, 43400 UPM Serdang Selangor Darul Ehsan, Malaysia

2. Department of Mathematics, Faculty of Science, University Putra Malaysia, 43400 UPM Serdang, Selangor Darul Ehsan, Malaysia

3. Department of Population Science Human Resource Development, Faculty of Science, University of Rajshahi, Rajshahi- 6205, Bangladesh

\begin{abstract}
Background: All over the world the prevalence of Human Immunodeficiency Virus (HIV)/Acquired Immune Deficiency Syndrome (AIDS) has became a stumbling stone in progress of human civilization and is a huge concern for people worldwide.

Objective: To determine the social and health factors which contribute to increase the size of HIV epidemic globally.

Methods: The country level indicators of HIV prevalence rates, are contraceptive prevalence rate, physicians density, proportion of Muslim populations, adolescent fertility rate, and mean year of schooling were compiled of 187 countries from the United Nations (UN) agencies. To extract the major factors from those indicators of the later five categories, backward multiple regression analysis was used as the statistical tool.

Results: The national HIV prevalence rate was significantly correlated with almost all the predictors. Backward multiple linear regression analysis identified the proportion of Muslims, physicians density, and adolescent fertility rate are as the three most prominent factors linked with the national HIV epidemic.

Conclusions: The findings support the hypotheses that a higher adolescent fertility rate in the population is the adverse effect of premarital and extramarital sex that leads to longer period of sexual activity which increases the risk of HIV infection. On the hand, and cultural restrictions of Muslims and sufficient physicians will decelerate the spread of HIV infections in the society.
\end{abstract}

Keywords: HIV/AIDS epidemic, adolescent fertility rate, contraceptive prevalence rate African Health Sciences 2013; 13(2): 301 - 310 http://dx.doi.org/10.4314/ahs.v13i2.15

\section{Introduction}

All over the world the prevalence of Human Immunodeficiency Virus (HIV)/Acquired Immune Deficiency Syndrome (AIDS) has became a stumbling stone in progress of human civilization and is a huge concern for people worldwide. Since the identification of the HIV in the early 1980s, much has been learned about how the virus is transmitted and how it attacks the body's immune system and causes the AIDS. The HIV/AIDS epidemic has grown on an unprecedented scale in the last three decades since it was first recognized, and now it is considered a global crisis. The countries, which have

\begin{tabular}{|l|}
\hline *Corresponding author: \\
Dr. Md Nazrul Islam Mondal \\
Institute for Mathematical Research \\
University Putra Malaysia, 43400 UPM Serdang \\
Selangor Darul Ehsan, Malaysia \\
Phone: +60389468907 \\
E-mail: nazrul_ru@yahoo.com \\
\hline
\end{tabular}

African Health Sciences Vol 13 Issue 2 June 2013 to fight with the concentrated or generalized HIV/ AIDS epidemic, are facing enormous socioeconomic problems. In 2011, the total number of people living with HIV was 34.2 million, newly infected with HIV was 2.5 million, and AIDS deaths was 1.7 million ${ }^{1}$. The cases have been reported in all regions of the world, but largest part those existing with HIV (97\%) reside in low and middle income countries, particularly in sub-Saharan Africa ${ }^{1}$. The majority new infections are transmitted heterosexually, while the risk factors vary. In some countries, men who have sex with men (MSM), injecting drug users (IDUs), and sex workers (SW) are at significant risk. Most people living with HIV or at risk for HIV do not have access to prevention, care, and treatment, and there is still no cure ${ }^{1}$.

HIV/AIDS is a burning public health issue all over the world. The HIV disease is a leading cause of deaths worldwide and the number one cause of 
death in Africa. HIV primarily affects those in their most productive years; about half of new infections are among those below the age 25 years ${ }^{1}$. The women, especially younger women, are biologically more susceptible to HIV. As a result, young women are twice more likely to become infected with HIV than that of male globally. Women embodied about half of all people living with HIV globally, and more than half $(60 \%)$ in sub-Saharan Africa. HIV is the leading cause of deaths among women in their reproductive age (15-49 years) ${ }^{1}$. Gender inequalities, differential access to services, and sexual violence increase women's vulnerability to HIV. Young adolescent girls are not only biologically more susceptible to HIV infection; they are more likely to have older sexual and partners who are IDUs, consequently increasing their potential exposure to $\mathrm{HIV}^{2}$. An intersection of two infections disorders can have a synergistic effect on mortality and morbidity. In fact, HIV not only affects the health of individuals, it impacts households, communities, and the development and economic growth of nations.

The prevalence of HIV disease levels can vary considerably between different countries and between different populations within a country as well as globally. It is associated with much more variation in socio-demographic and health factors than is admitted in broad statements and projections about pandemics based on crude epidemiological data. Differences between cultures and countries in terms of contraceptive use, educational attainment, circumcision practices and access to treatment for sexually transmitted diseases (STDs) can therefore explain much of the observed variation in HIV prevalence levels. These differences may relate to and reflect standards and styles of living, especially in family life, rearing of children, adolescence and occupational preferences. This diversity is usually attributable to a range of socioeconomic, biological, demographic and behavioral factors ${ }^{3}$. The positive relationship between lower socioeconomic status and HIV progression is well documented ${ }^{4-6}$. Numerous studies have been conducted globally and especially in sub-Saharan Africa on risk factors of HIV infection. These determinants or risk factors can be grouped into two categories, including sexual behavioral risk factors ${ }^{7-11}$ and influential risk factors ${ }^{12-}$

15. Thus, much has been known about what determines the spread as well as prevention of the HIV/AIDS epidemic. From best of our knowledge a few studies have been undertaken on the associations of socioeconomic and health factors with HIV/AIDS epidemic in the global context. So, it will differ from other studies in several important aspects and it will use a broader range of explanatory variables based on more current and relevant data to offer a more comprehensive view of HIV implication.

This study examined how strongly social and health factors influence the sizes of HIV/AIDS epidemic by using best known statistical tools. Focusing on HIV/AIDS pandemic in the globe, and this can offer to the policy makers in socio-health options to combating the disease and its routes of infection.

\section{Methods}

The HIV / AIDS epidemic has crossed all boundaries and has brought up issues, which have wide medical, social, legal and economic ramifications. The epidemic is extremely heterogeneous in its prevalence. Therefore, the country-level indicators of HIV prevalence rates, contraceptive prevalence rates, physicians density, proportion of Muslim populations, adolescent fertility rates, and mean years of schooling were compiled. Data sources were the following United Nations (UN) agencies: World Health Organization (WHO) ${ }^{16}$, United Nations Development Programs (UNDP) ${ }^{17}$, Population Reference Bureau $(\mathrm{PRB})^{18}$, and Pew Research Center $(\mathrm{PRC})^{19}$. All the variables, their sources and descriptions are included in the table. These factors are assumed to play the important roles in explaining the differences in HIV prevalence of the countries in the world. The WHO Member States are grouped into six geographical regions: Africa (AFR), Americas (AMR), Eastern Mediterranean (EMR), Europe (EUR), South-East Asia (SEAR) and Western Pacific $(\mathrm{WPR})^{16}$. The distribution of the presented variables is compared between the six WHO regions as indicated in table 1 below.

The statistical analyses concentrated on 187 countries because of the availability of required data. The ecological data has been used for univariate analysis, to carry out the description of the variables and their attributes on data in list; bivariate analysis, to find the correlations among the variables; and finally, backward multiple linear regression analysis, to examine the average relationship between HIV prevalence rate and socio-health factors and find out the most prominent affecting factors. 
Table 1: Variables, their descriptions and sources

\begin{tabular}{|c|c|c|}
\hline Variables & Descriptions & Sources \\
\hline $\begin{array}{l}\text { HIV prevalence rate } \\
\text { per } 100 \text { populations. }\end{array}$ & Estimated number of adult population aged $15-49$ years & $\mathrm{WHO}^{16}, \mathrm{PRB}^{18}$ \\
\hline $\begin{array}{l}\text { Contraceptive } \\
\text { prevalence rate }\end{array}$ & $\begin{array}{l}\text { Percentages of women of reproductive age (ages 15-49) } \\
\text { who are using, or whose partners are using, any modern } \\
\text { or traditional form of contraception. }\end{array}$ & $\mathrm{PRB}^{18}$ \\
\hline Physicians density & Number of physicians per ten thousand populations & $\mathrm{WHO}^{16}$ \\
\hline $\begin{array}{l}\text { Proportion of Muslim } \\
\text { populations }\end{array}$ & Percentage of population that is Muslim & $\mathrm{PRC}^{19}$ \\
\hline Adolescent fertility rate & $\begin{array}{l}\text { Number of births to women ages } 15-19 \text { per } 1000 \\
\text { women ages } 15-19 \text {. }\end{array}$ & $\mathrm{UNDP}^{17}$ \\
\hline Mean year of schooling & $\begin{array}{l}\text { Average number of years of education received by } \\
\text { people } 25 \text { and older, converted from education attainment } \\
\text { levels using official durations of each level. }\end{array}$ & $\mathrm{UNDP}^{17}$ \\
\hline
\end{tabular}

The univariate multiple regression statistics examined each independent variable with HIV prevalence rate as the dependent variable. The underlying multiple linear regression model corresponding to each variable is:

$y=\beta_{0}+\beta_{1} X_{1}+\beta_{2} X_{2}+\beta_{3} X_{3}+\ldots \ldots \ldots+\beta_{k} X_{k}+\varepsilon$, (1)

where $Y$ is the response variable (HIV prevalence rate), $X_{i}(i$ $=1,2,3, \ldots, k$ ) are the predictor variables (independent variables), $\beta_{0}$ is the intercept term, $\beta_{1}, \beta_{2}, \ldots \ldots \ldots . . . \beta_{k}$ are the unknown regression coefficients, and $\mathcal{E}$ is the error term wih a $\mathrm{N}\left(0, \mathrm{O}^{2}\right)$. In multiple regression analysis, an important assumption is that the explanatory variables are independent of each other, i.e., there is no relationship between the explanatory variables to estimate the ordinary least squares (OLS). However, in some applications of regression, the explanatory variables are related to each other, is known as the multicollinearity problem ${ }^{20}$. In this study, a variance inflation factor (VIF) was used to check for the multicollinearity problem among the predictor variables. The variance inflation for independent variables $X_{j}$ is:

$$
V T F_{j}=\frac{1}{1-R_{j}^{2}}, \quad j=1,2 \ldots \ldots \ldots \ldots . . . P,
$$

where $p$ is the number of predictor variables and

is the square of the multiple correlation coefficient of the $j$ th variable with the remaining ( $p$ 1) variables, where: i. if $0<\mathrm{VIF}<5$, there is no evidence of a multicollinearity problem;

ii. if $5<\mathrm{VIF}<10$, there is a moderate multicollinearity problem; and

iii. if VIF $>10$, there is a serious multicollinearity problem of variables.

All statistical analyses were performed using SPSS (version 16.0).

\section{Results}

HIV/AIDS, a pandemic disease, has creating severe public health problem all over the world. A total of 187 countries were included in this study. Univariate, bivariate and backward multiple regression approaches have been applied as the statistical tools. Effects of contraceptive prevalence rate, physicians density, proportion of Muslim population, adolescent fertility rate, and mean year of schooling on HIV prevalence rate are examined here in turn.

\section{Univariate analysis}

Background statistics of predictor and response variables explained the urgent threats for globally and WHO regions as presented in tables 2 and 3 respectively. Table 1 explains the maximum and minimum values for all the cases under study as well as their means, medians, and standard deviations (SD) to explore the main features of data of the countries. 
Table 2: Descriptive statistics of the dependent and independent variables of all countries

\begin{tabular}{|c|c|c|c|c|c|c|c|}
\hline Variables & $\mathbf{N}$ & Minimum & Maximum & Mean & Median & SE Mean & SD \\
\hline HIV prevalence rate $(\mathrm{Y})$ & 163 & .00 & 25.90 & 1.7493 & .3250 & .32808 & .18866 \\
\hline Contraceptive prevalence rate $\left(\mathrm{X}_{1}\right)$ & 173 & 3.00 & 89.00 & 49.254 & 51.00 & 1.71433 & 2.5485 \\
\hline Physicians density $\left(\mathrm{X}_{2}\right)$ & 178 & .10 & 64.00 & 15.547 & 11.00 & 1.08161 & 4.4305 \\
\hline Proportion of Muslim population $\left(\mathrm{X}_{3}\right)$ & 185 & .10 & 99.70 & 25.390 & 5.000 & 2.72866 & 7.1138 \\
\hline Adolescent fertility rate $\left(\mathrm{X}_{4}\right)$ & 187 & 2.30 & 207.10 & 52.774 & 42.70 & 3.24159 & 4.3281 \\
\hline Mean year of schooling $\left(\mathrm{X}_{5}\right)$ & 187 & 1.20 & 12.60 & 7.6166 & 7.500 & .21595 & .95309 \\
\hline
\end{tabular}

$\mathrm{N}=$ Number of countries, SE Mean=Standard error of mean, $\mathrm{SD}=$ Standard deviation

Table 3 explains clearly that the HIV prevalence rate is the highest $($ Mean $=5.309$, Maximum $=25.90)$ in the Africa region with lowest contraceptive prevalence rate $($ Mean $=29.659$, Minimum $=3$ ), lowest physicians density (Mean $=2.563$, and Minimum $=.10)$, highest adolescent fertility rate $($ Mean $=103.28$, Maximum $=207.10)$, and lowest mean year of schooling $($ Mean $=4.735$, Minimum $=1.20$ ) among the WHO regions. On the other hand,
HIV prevalence rate is seen the lowest $($ Mean $=.239$, Minimum $=0)$ in the European region with highest contraceptive prevalence rate (Mean $=63.309$, Maximum $=89$ ), highest physicians density (Mean $=31.949$, Maximum $=60.4$ ), lowest adolescent fertility rate $($ Mean $=19.216$, Minimum $=4.6)$, and highest mean year of schooling (Mean $=10.453$, Maximum $=12.6$ among the WHO regions.

Table 3: Descriptive statistics (mean, maximum and minimum) of the dependent and independent variables by WHO regions

\begin{tabular}{|c|c|c|c|c|c|c|}
\hline \multirow[b]{2}{*}{ Variables } & \multicolumn{3}{|c|}{ WHO Regions } & \multirow[b]{2}{*}{ EUR } & \multirow[b]{2}{*}{ EMR } & \multirow[b]{2}{*}{ WPR } \\
\hline & AFR & AMR & SEAR & & & \\
\hline HIV prevalence rate $(\mathrm{Y})$ & $5.309(.10,25.90)$ & $.880(.10,3.10)$ & $.348(.05,1.3)$ & $.239(0,1.2)$ & $.253(0,2.3)$ & $.274(.05,1.5)$ \\
\hline $\begin{array}{l}\text { Contraceptive prevalence } \\
\text { rate }\left(\mathrm{X}_{1}\right)\end{array}$ & $29.659(3.00,76)$ & $62.97(32,81)$ & $52.182(22,80)$ & $63.309(14,89)$ & $42.579(8,79)$ & $\begin{array}{l}48.909(21, \\
85)\end{array}$ \\
\hline Physicians density $\left(\mathrm{X}_{2}\right)$ & $2.563(.10,18.8)$ & $16.54(3.7,64)$ & $5.764(.2,19.7)$ & $\begin{array}{r}31.949(11.5 \\
60.4)\end{array}$ & $\begin{array}{r}14.516(2.1 \\
35.4)\end{array}$ & $\begin{array}{r}11.987(.5 \\
29.9)\end{array}$ \\
\hline $\begin{array}{l}\text { Proportion of Muslim } \\
\text { population }\left(\mathrm{X}_{3}\right)\end{array}$ & 28.48(.10, 99.1) & $.812(.1,7.2)$ & $\begin{array}{l}47.945(2.3 \\
103.4)\end{array}$ & $\begin{array}{c}\text { 17.648(.1) } \\
99.2)\end{array}$ & $\begin{array}{c}90.353(59.3 \\
99.7)\end{array}$ & $\begin{array}{r}12.196(.1 \\
98.2)\end{array}$ \\
\hline $\begin{array}{l}\text { Adolescent fertility rate } \\
\left(\mathrm{X}_{4}\right)\end{array}$ & $103.28(7.3,207.1)$ & $\begin{array}{l}64.371 \\
(14,1127)\end{array}$ & $28.8(.1,98.4)$ & $\begin{array}{r}19.216(4.6, \\
44.7)\end{array}$ & $\begin{array}{r}35.516(3.2 \\
118.7)\end{array}$ & $\begin{array}{r}28.587(2.3, \\
70.3)\end{array}$ \\
\hline Mean year of schooling & $4.735(1.2,9.4)$ & $\begin{array}{r}8.309(4.1 \\
12.4)\end{array}$ & $5.409(2.3,11.6)$ & $\begin{array}{r}10.453(6.5 \\
12.6\end{array}$ & $\begin{array}{c}6.274(2.5 \\
9.4)\end{array}$ & $\begin{array}{r}8.813(4.3 \\
12.5)\end{array}$ \\
\hline
\end{tabular}

The numbers inside the parenthesis indicate minimum and maximum values respectively

\section{Bivariate analysis}

The correlation coefficients $(r)$ were derived to examine direction, strength and significance of linear relationships between the variables included in the study as shown in table 4 .

Table 4: Correlation between the variables that were examined

\begin{tabular}{|c|c|c|c|c|c|c|}
\hline & $\mathbf{Y}$ & $\mathbf{X}_{1}$ & $\mathbf{X}_{2}$ & $\mathbf{X}_{3}$ & $\mathbf{X}_{4}$ & $\mathbf{X}_{5}$ \\
\hline HIV prevalence rate $(\mathrm{Y})$ & 1 & & & & & \\
\hline Contraceptive prevalence rate $\left(\mathrm{X}_{1}\right)$ & $-.210^{*}$ & 1 & & & & \\
\hline physicians density $\left(\mathrm{X}_{2}\right)$ & $-.347 * *$ & $.604 * *$ & 1 & & & \\
\hline Proportion of Muslim population $\left(\mathrm{X}_{3}\right)$ & -.154 & $-.348^{* *}$ & $-.235^{* *}$ & 1 & & \\
\hline Adolescent fertility rate $\left(\mathrm{X}_{4}\right)$ & $.411 * *$ & $-.549 * *$ & $-.619 * *$ & .054 & 1 & \\
\hline Mean year of schooling $\left(X_{f}\right)$ & $-.243 * *$ & $.687 * *$ & $.764 * *$ & $-.354 * *$ & $-.674 * *$ & 1 \\
\hline
\end{tabular}

*Significant at $\mathrm{p}<.05$ level, and ${ }^{* *}$ Significant at $\mathrm{p}<.01$ level 
The significant similar relationships were found between HIV prevalence rate and adolescent fertility rate $(r=.411, \mathrm{p}<.01)$. On the other hand, significant opposite relations were found of contraceptive prevalence rate $(r=-.210, \mathrm{p}<.05)$, physicians density $(r=-.347, \mathrm{p}<.01)$ and mean year of schooling $(r=$ $-.243, \mathrm{p}<.01)$ with HIV prevalence rate. Again, physicians density $(r=.604, \mathrm{p}<.01)$ and mean year of schooling $(r=.687, \mathrm{p}<.01)$ were positively correlated and proportion of Muslim population $(r$ $=-.235, \mathrm{p}<.01)$ and adolescent fertility $(r=-.549$, $\mathrm{p}<.01)$ were negatively correlated with contraceptive prevalence rate. Mean year of schooling $(r=764$, $\mathrm{p}<.01)$ was positively correlated and adolescent fertility rate $(r=-.619, \mathrm{p}<.01)$ and proportion of
Muslim population $(r=.235, \mathrm{p}<.01)$ were negatively correlated with the physicians density. Mean year of schooling $(r=-.674, \mathrm{p}<.01)$ was negatively significantly correlated with adolescent fertility rate.

\section{Backward multiple regression analysis}

Three sets of multiple linear regressions were conducted where HIV prevalence rate was the dependent variable and contraceptive prevalence rate, physicians' density, proportion of Muslim populations, adolescent fertility rate, and mean year of schooling were the predictors as presented in table 5. Since, the VIF for all predictors were less than five, so there is no evidence of a multicollinearity problem.

Table 5: Backward multiple linear regression models explaining the HIV epidemic

\begin{tabular}{lllllll}
\hline Explanatory variables & \multicolumn{6}{c}{ Standardized coefficients and variance inflation factors (VIF) } \\
\cline { 2 - 7 } & Model 1 & VIF & Model 2 & VIF & Model 3 & VIF \\
\hline Contraceptive prevalence rate $\left(\mathrm{X}_{1}\right)$ & -.021 & 2.140 & & & & \\
Physicians density $\left(\mathrm{X}_{2}\right)$ & $-.270^{*}$ & 2.468 & $-.273^{*}$ & 2.407 & $-.208^{*}$ & 1.656 \\
Proportion of Muslim & $-.191^{*}$ & 1.319 & $-.187^{*}$ & 1.247 & $-.219^{* *}$ & 1062 \\
population $\left(\mathrm{X}_{3}\right)$ & & & & & & \\
Adolescent fertility rate $\left(\mathrm{X}_{4}\right)$ & $.343^{* *}$ & 2.093 & $.348^{* *}$ & 1.997 & $.299^{* *}$ & 1.581 \\
Mean year of schooling $\left(\mathrm{X}_{5}\right)$ & .142 & 3.485 & .134 & 3.210 & & \\
Adjusted $\mathrm{R}^{2}$ & .608 & & .714 & & .811 & \\
\hline
\end{tabular}

${ }^{*}$ Significant at $\mathrm{p}<.05$ level, and ${ }^{* *}$ Significant at $\mathrm{p}<.01$ level

In the above three models, contraceptive prevalence rate, physicians density, and Muslim populations indicated negative associations where as adolescent fertility rates and mean year of schooling identified positive associations with HIV prevalence rate. In Model 1, all the predictors were included. Among these predictors physicians density, proportion of Muslim populations, and adolescent fertility rate were found as the significant predictors of HIV prevalence rate. All the predictors except contraceptive prevalence rate were retained in Model 2, where physicians' density, proportion of Muslims, and adolescent fertility rate were found as the significant predictors of HIV prevalence rate. Finally, in Model 3, physicians' density, proportion of Muslims and adolescent fertility rate were retained and all these were significant predictor to be explained the HIV prevalence rates.

\section{Discussion}

In this study, we have clarified that physicians' density, proportion of Muslim populations, and adolescent fertility rates, were significant predictors of HIV prevalence rates in the globe. Significant associations between contraceptive prevalence rates and mean year of schooling were also found. These findings are also important because they indicate the link between health and policy or economics at the country level, and also highlight the direction of health policy in the current world.

\section{Contraceptive prevalence rate}

Contraceptive using is a well known determinant of HIV prevalence indicator at the country level which is playing the vital role in preventing HIV transmission. Globally, contraceptive use and its agreement is related to the range of methods available, patient choice, prevalent health and religious beliefs, perceptions of method effectiveness, and side effects $^{21}$. Despite the fact that the contributions of contraception to reducing mother to child transmission (MTCT) have been well documented ${ }^{22-}$ ${ }^{24}$. But, it is observed that the contraceptive prevalence rate is the lowest (mean $=29.66)$ in the highest HIV prevalence region (mean $=5.01$ ), Africa. However, in some countries where the HIV 
prevalence rate is high, contraceptive use is reasonably low. High rates of unmet contraceptive need and unplanned pregnancy have been reported among HIV infected women in Malawi, South Africa, and $\mathrm{Uganda}^{25-28}$. In Uganda, the contraceptive prevalence rate among currently married women is $24 \%$ which is very low compared to the countries Ireland (89\%), Norway $(88 \%)$, etc. ${ }^{16}$.

Women with HIV infection may wish to plan pregnancy limit their family or avoid pregnancy. The choice of contraception in people living with HIV is constrained by the need to prevent both sexual transmission of HIV and unwanted pregnancies as well as to protect MTCT. The correct and consistent use of male condoms prevents HIV transmission to the partner ${ }^{29-30}$. Compared with inconsistent use, consistent condom use reduces the risk of seroconversion to half among HIV-discordant couples $^{31}$ and reduces the risk of acquiring other sexually transmitted infections (STIs). Unfortunately, the knowledge of contraception and access to family planning remain limited among women living with HIV and AIDS in different contexts ${ }^{32}$. Oral contraceptives, intrauterine devices (IUDs), and sterilization are highly effective methods of contraception, which however do not prevent HIV transmission.

\section{Physicians' density}

People living with HIV and AIDS (PLHA) need a variety of healthcare and social support, because of their vulnerability to opportunistic infections and their progressive disease. Health care provides continue to have important role in care and support for PLHA. The health care providers are always in the pursuit of better healthcare interventions for the HIV infected population. Physicians' role is essential since this is a privileged point of global attention, counseling and support for the HIV patients. The global shortage of health workers is estimated at over 4 million, with 57 countries experiencing severe shortage; defined as fewer than 0.23 doctors, nurses, or midwives per ten thousand people ${ }^{16}$. This translates into nearly a billion people who have no access to a health worker of any kind of the oneseventh of the world's population. The physicians investigate the risk factors and risk practices, inform, prevent new cases and, in the infected people, monitor the evaluation, supporting and comforting. Physicians ask the HIV infected patients more questioning about their sex lives and needle-using habits in order to slow the spread of HIV.
The majority of identified HIV-positive people are in contact with health care providers ${ }^{6}$. Importantly, an awful lot of those HIV infected people continue to be sexually active and to spread the infection to others. The patients pay attention to their physicians' advice, and even the simplest messages can have an important impact on patients' health practices. They deliver prevention messages, providing condoms and, when appropriate, referring patients to outside prevention services. They also encourage patients to notify partners of their infections and to help patients contact health departments to arrange for notification of partners who are not already informed.

The contribution of physicians/health workers are well documented and especially to turning the tide on HIV/AIDS. The different types of health workers- doctors, nurses, midwives, clinical officers, rural medical practitioners, and others are contributing to prevent HIV infection and they acknowledged by WHO. Sometimes the health workers have to work jointly in the national and or international organizations. An international organization, 'IntraHealth' work with health workers, especially in Africa and Central America, is making a difference. In Ethiopia, the IntraHealth works to strengthen prevention of PMTCT of HIV and a satisfactory consequence is found. It was started working in PMTCT in 2003; there were no PMTCT services at any government clinic in Ethiopia. Now IntraHealth supports these services in 511 clinics where a good number of frontline physicians are working continuously.

\section{Proportion of Muslims}

The cultural and sexual practices between the religions are different. The low prevalence group is largely Muslim and the high prevalence group is largely nonMuslim; a finding also of $\mathrm{Gray}^{23}$. Drug abuse, homosexuality, extramarital and premarital sex are strongly prohibited in Muslim religion. The impact of religion can be clearly seen from the HIV prevalence in South Africa and Uganda and by the difference that the classification and enumeration of HIV may change with national borders. The high prevalence countries in the Africa region are identified in table 3. The highest HIV/AIDS prevalence countries in sub-Saharan are Swaziland $(25.9 \%)$, Botswana (24.8\%), Lesotho $(23.6 \%)^{16}$. The conventional explanation is that the syndrome has spread heterosexually into neighboring and affluent South Africa $(17.8 \%)$. But, Botswana is almost 
bordered to the north by low prevalence Angola $(2 \%)$. The question arises then of what it is that stops heterosexual spread northwards but permits it southwards.

The Central African Republic is a high prevalence $(4.7 \%)$ country. It is bordered by the low prevalence countries of the Congo Democratic Republic $(1.25 \%)^{18}$, Chad (3.4\%) and Sudan $(1.1 \%)^{16}$. Another anomaly is found on the west coast of Africa. Here lies the small but high prevalence country Guinea Bissau (2.5\%). This is bordered by Guinea (1.3\%), and Senegal (0.9\%). Similar reservations must be held for other socioeconomic and health statistics. Despite these reservations the results are reasonably and perhaps surprisingly consistent, especially in association between the high prevalence in non-Muslim and lower prevalence in predominantly Muslim countries.

\section{Adolescent fertility rate}

Adolescence is a transitional period from childhood to adulthood characterized by significant physiological, psychological and social changes. According to the definition of WHO, the age group of 10-19 and 15-24 years of age as adolescents and youth respectively. Worldwide, adolescents suffer from a disproportionate share of early marriage, unwanted pregnancies, unsafe abortions, STIs including HIV/AIDS, female genital mutilation, malnutrition and anemia, infertility, sexual and gender based violence, and other serious reproductive health problems ${ }^{34}$. Adolescent fertility also known as teenage fertility refers to a condition where woman has given live birth before the age of 20 years.

Throughout the world, over 14 million adolescents aged 15-19 years give births annually ${ }^{35}$. It is estimated that, in the last decade, over 58 million girls were married before the age of 18 years; of which, 15 million were 10-14 years old. Many were married against their will, often experiencing violence $^{36}$. The average fertility rate among teenagers in the least developed countries is five times greater than that of the more developed regions (table 3). On an average, one third of young women in developing countries give birth before age of 20 years, and each year, an estimated 14 million adolescents between the ages of 15 and 19 give birth globally and more than $90 \%$ of these live births occur in developing countries ${ }^{37}$. An estimated 70,000 teenaged girls die each year during pregnancy and childbirth and more than one million infants born to adolescent girls die before their first birthday.
Because of such a grave health consequences teenage pregnancies are termed a death sentence in poorest countries. About 2 millions or more of them suffered chronic illness or disabilities, shame and abandonment. Moreover, each year 2.2 to 4 million adolescents resort to unsafe abortion ${ }^{37}$. Adolescent pregnancy and childbearing have distinct and important deleterious consequences at global, societal and personal levels.

Globally, population growth is more rapid when women have their first child in their teenage as early initiation of giving birth lengthens the reproductive period and subsequently increases fertility. At the societal level, the strong association observed between adolescent childbearing and low levels of educational achievement brings (table 4). Individually, adolescent fertility is associated with adverse maternal and child health outcomes including obstructed labor, low birth weight, fetal growth retardation, and high infant and maternal mortality rate $^{38}$. The prevalence of forced first sex among adolescent girls younger than 15 years ranges between $11 \%$ and $48 \%$ globally ${ }^{39}$. This potentially leads to higher prevalence of sexual activity among unmarried girls and expose them to unplanned pregnancies, unsafe abortion and contracting STIs including HIV $/ \mathrm{AIDS}^{40}$. Adolescents who sell sex or use drugs are at higher risk of HIV infection, but they may not have access to information, sterile injecting equipment and services such as HIV testing and support ${ }^{39}$.

\section{Mean years of schooling}

It is obvious that educated girls and women can protect themselves and their families from HIV infection and it is considered as the key to turning the tide. When girls have access to education, they are less likely to marry early ${ }^{41}$. The educated girls and women have more options to choose marriage, to decide when and with whom they have sex, to ask their husbands to be faithful, to negotiate condom use, to live their lives free from violence, to earn incomes adequate to feed their families which are the ability to protect them from HIV. Poor education has been indicated as a major determinant in infection in Africa ${ }^{3}$.

This study also indentified education as a significant important determinant of HIV prevalence rate in the globe. Violence and the threat of violence hampers women's, including young women's and adolescents, ability to protect themselves from HIV infection and to make smart decisions regarding 
sexual health. The health education is important in promoting health behavior and preventing disease. Specifically, health education is a powerful tool in reducing the HIV disease burden. This type of education provides information to individuals about the disease, how it is transmitted, how they can take precautionary measures to help prevent the transmission of HIV, and what steps to take if they suspect that they have contracted the disease. It emphasizes the concept of self-empowerment and it informs individuals about the importance of prevention and safe behaviors to prevent the infection and transmission of HIV. In addition, to creating the opportunity to empower individuals, education can create a hopeful outlook on a disease. HIV/AIDS related education can help to develop standards of behavior that create a positive state of body, mind and spirit ${ }^{41}$. Individuals can strengthen their ability to cope with the disease and take initiative to adhere to the treatments outlined in their disease management program. On the other hand, poor literacy has been associated with poor health and negative treatment outcomes ${ }^{42}$. Being able to understand the medical treatments is crucial for treatment adherence, especially for individuals with HIV/AIDS, whose treatments can seem complicated if not explained properly by their physician. Furthermore, poor personal knowledge and understanding of health issues is also a result of poor health literacy. Literacy can pose as a long-term barrier in proper treatment adherence. Thus, only education can play an important role in reducing the burden of HIV/AIDS by increasing health literacy and creating opportunities for prevention and better disease management.

\section{Conclusion}

This ecological study assessed the social and health risk factors that could possibly be associated with HIV infections in the globe. The higher contraceptive prevalence rates, availability of physicians, and education have played the significant roles in preventing HIV in the globe. On the other hand, the higher adolescent fertility rate and lower proportion Muslim population contribute to enhance the epidemic. Many questions are raised by the rapid spread of the HIV disease globally.

The differences of HIV prevalence in the present world are the indications of the general level of health in different countries, within countries and between individuals with differing life styles and cultures. These findings have implications for the development of interventions to reduce HIV transmission risk behavior in the population. Good health is an important component of human wellbeing and the improvements in health and life expectancy are likely to contribute to greater economic growth and human resource development. In reality, HIV/AIDS affects not only the infected person, but also his or her family, community, and country. At the household level, people have loss of companionship and income. At the community and national levels, they experience loss of productivity because of absenteeism and deaths.

The high prevalence of HIV infections is unexpected, therefore need to further investigate the association between HIV status and socioeconomic and health parameters. The international organizations have to increase the number of health workers in the HIV affected countries through supporting education and training related to health. Since adolescent fertility is felt to be a problem, concerted efforts are needed to empower adolescents to fight early cohabitation, promote education and encourage the utilization of family planning.

\section{Acknowledgement}

The authors are very grateful to the Laboratory of Computational Statistics and Operations Research, Institute for Mathematical Research (INSPEM), University Putra Malaysia (UPM); Malaysia for granting a Visiting Scientist Fellowship to complete this study.

\section{References}

1. WHO/UNAIDS/UNICEF. Global HIV/ AIDS Response; November 2011.

2. Ministry of Health and Family Welfare (MOHWF). National HIV Serological Surveillance, 2011; Bangladesh. National AIDS/ STD Program, Directorate General of Health Services, Ministry of Health and family Welfare, Bangladesh 2012.

3. Johnson L. and Budlender D. HIV risk factors: a review of the demographic, socio-economic, bio-medical and behavioral determinants of HIV prevalence in South Africa. CARE Monograph No. 8, 2002; Centre for Actuarial Research, University of Cape Town.

4. Muula AS. HIV infection and AIDS among young women in South Africa. Croat Med J. 2008; 49(3):423-435.

5. Tladi LS. Poverty and HIV/AIDS in South Africa: An empirical contribution. Sabara: 
Journal of Social Aspects of HIV/AIDS Research Alliance 2006; 3(1):369-381.

6. Ackermann L, De Klerk GW. Social factors that make South African women vulnerable to HIV infection. Health Care Women Int. 2002; 23:163-172.

7. Quigeley M, Munguiti K, Grosskuth $\mathrm{H}$, et. al. Sexual behavior patterns and other risk factors for HIV infection in rural Tanzania: A CaseControl Study. AIDS 1997, 11:237-248.

8. Gomo E, Chibatamoto PP, Chandiwana SK, et al. Risk Factors for HIV Infection in Rural Cohort in Zimbabwe: A Pilot Study. Cent Afr J Med 1997, 43:350-354.

9. Bassett MT, McFarland WC, Ray S, et. al., Risk Factors for HIV Infection at Enrollment in an Urban Male Factory Cohort in Harare, Zimbabwe. J Acquir Immune Syndr Hum Retrovol 1996, 13:287-293.

10. Nunn AJ, Kengeya-Kayondo JF, Malamba SS, et. al. Risk Factors for HIV-1 infection In adults in a rural Uganda community: a population study. AIDS 1994, 8:81-86.

11. Chao A, Bulterys M, Musanganire F, et. al. Risk Factors Associated with Prevalent HIV-1 Infection among Pregnant Women in Rwanda. National University of Rwanda-Johns Hopkins University AIDS Research Team. Int J Epidemiol 1994, 23:371-380.

12. Craven BM, and Stewart GT. Economic implications of socio-cultural correlates of HIV/AIDS: an analysis of global data. Applied Economics, 2012. 45, 1789-1800.

13. Andoh SY, Umezaki M, Nakamura K, et al. Correlation between national income, HIV/ AIDS and political status and mortalities in African countries. Public Health (2006)120, 624633.

14. Drain PK, Smith JS, Hughes JP, et al. Correlates of National HIV Seroprevalence: An Ecologic Analysis of 122 Developing Countries. J Acquir Immnue Defic Syndr Vol. 35(4). 2004.

15. Buve A, Carael M, Hayes R, et. al. Variations in HIV Prevalence between Urban areas in SubSaharan Africa: Do We Understand them? AIDS 1995, 9(suppl A):S103-S109.

16. WHO. World Health Statistics 2011, World Health Organization (WHO), Geneva, Switzerland.

17. UNDP. Human Development Report 2011. United Nations Development Program UN Plaza, New York, NY 10017, USA.
18. PRB. World Population Data Sheet 2012, Population Reference Bureau (PRB), Washington DC, USA.

19. PRC. Mapping the Global Muslim Population, Pew Forum on Religion \& Public Life, Pew Research Center (PRC), 2009; Washington DC, USA.

20. Chatterjee S. and Hadi AS. Regression Analysis by Example, 4th Edn, 2006. John Wiley, New York.

21. Mitchell HS, Stephens E. Contraception choice for HIV positive women. Sex. Transm. Infect. 2004, 80: 167-173.

22. Reynolds HW, Janowitz B, Wilcher R, and Cates W. Contraception to prevent HIV-positive births: current contribution and potential costsaving in PEPFAR countries. Sex Transm Infect 84 (Suppl 2), 2008: ii49-ii53.

23. Reynolds HW, Janowitz B, Homan R, Johnson $\mathrm{L}$. The value of contraception to prevent perinatal HIV transmission. Sex Trans Dis, 2006; 33:350-356.

24. Reynolds HW, Steiner MJ, Cates W. Contraception's proved potential to fight HIV. Sex Transm Inf, 2005; 81: 184-185.

25. Laher F, Todd CS, Stibich MA, Phofa R, Behane X, Mohapi L, Gray G. A qualitative assessment of decisions affecting contraceptive utilization and fertility intentions among HIVpositive women in Soweto, South Africa. AIDS Behav 2009; 13 (Suppl 1):47-54.

26. Taulo F, Berry M, Tsui A, Makanani B, Kafulafula G, Li Q, Nkhoma C, Kumwenda JJ, Kumwenda N, Taha TE. Fertility intentions of HIV-1 infected and uninfected women in Malawi: a longitudinal study. AIDS Behav 2009; 13 (Suppl 1):20-7.

27. Homsy J, Bunnell R, Moore D, King R, Malamba S, Nakityo R, Glidden D, Tappero J, Mermin J. Reproductive intentions and outcomes among women on antiretroviral therapy in rural Uganda: a prospective cohort study. PLOS ONE 2009; 4(1):e4149.

28. Hoffman IF, Martinson FE, Powers KA, Chilongozi DA, Msiska ED, Kachipapa EI, Mphande CD, Hosseinipour MC, Chanza HC, Stephenson R, Tsui AO. The yearlong effect of HIV-positive test results on pregnancy intentions, contraceptive use, and pregnancy incidence among Malawian women. J Acquir Immune Defic Syndr 2008; 47(4):477-83. 
29. Davis K, Welker S. The effectiveness of condoms in reducing heterosexual transmission of HIV. Fam. Plann. Perspect. 1999, 31: 272-279.

30. De Vincenzi I. Longitudinal study of human immunodeficiency virus transmission by heterosexual partners. N. Engl. J. Med.1994, 31:341-346.

31. Nicolosi A, Musicco M, Saracco A, Lazzarin A. Risk factors for woman-to-man sexual transmission of the human immunodeficiency virus. Italian Study Group on HIV Heterosexual Transmission. J. Acquired Immune Defic. Syndr., 1994; 7: 296-300.

32. Lindsay M, Grant J, Peterson H, Willis S, Nelson P, Klein L. The impact of knowledge of human immunodeficiency virus sero-status on contraceptive choice and repeat pregnancy. Obstet. Gyneco.1995; 85:675-679.

33. Gray PB. HIV and Islam: is HIV prevalence lower among Muslims? Social Science and Medicine, 58, 2004; 1751-6.

34. Stella N, Nakanyike M, Richard K. Adolescent Sexual and Reproductive Health in Uganda: A Synthesis of Research Evidence. New York and Washington: Alan Guttmacher Institute; 2004. Report No.14.

35. Alemayehu T, Haider Jemal, and Habte D. Determinants of Adolescent Fertility in Ethopia. Ethiop. J. Health Dev. 2010; 24(1).
36. UNICEF. Early Marriage: A Harmful Traditional Practice, 2005; UN Plaza, New York, NY 10017, USA.

37. UNFPA. Giving girls today and tomorrow. Breaking the cycle of adolescent pregnancy. New York; 2007.

38. Rafalimanana H. Adolescent fertility in the developing world: levels and trends in the 1990's and early 2000's. Paper presented at the annual of the population association of America, Los Angeles, California, from March 30, 2006 to April 1, 2006

39. WHO multi-country study on women's health and domestic violence against women: summary report of initial results on prevalence, health outcomes and women's responses. Geneva, World Health Organization, 2005.

40. Marston C, Cleland J. The effects of contraception on obstetric outcomes. Geneva: WHO; 2004.

41. Kelly MJ. What HIV/AIDS Can Do To Education, and What Education Can Do To HIV/AIDS. Presented at All Sub-Saharan Africa Conference on Education for All, 1999.

42. Williams MV, Parket RM, Baker DW, et al. Inadequate functional health literacy among patients at two public hospitals. JAMA, 1995; 274:1677-1682. 